\title{
Measles IgG Antibodies: Is There a Protective Role in COVID 19 Pandemic?
}

\author{
Amira M. AlBalakosy ${ }^{1}$, Mostafa Alfishawy ${ }^{2}$, Omnia M. El nabaway ${ }^{3}$, \\ Azza M. Hassan ${ }^{4}$, Mostafa A.A. Shamkh', Mahmoud M. Mahmoud ${ }^{5}$, \\ Ethar M.Badran ${ }^{1}$, Hany M. Dabbous ${ }^{1}$, Osama A. Ahmed ${ }^{6}$, Rana M. Taha ${ }^{7}$, \\ Ahmed F Sherief ${ }^{1}$ \\ ${ }^{1}$ Department of Tropical Medicine, Faculty of Medicine, Ain Shams University Abbasia \\ square, Cairo, Egypt. \\ ${ }^{2}$ Infectious Diseases Consultants and Academic Researchers of Egypt committee, \\ Alrawda island, Cairo, Egypt. \\ ${ }^{3}$ Department of Clinical Pathology, Faculty of Medicine, Ain Shams University, \\ Abbasia square, Cairo, Egypt. \\ ${ }^{4}$ Department of Community, Environmental and Occupational Medicine, Faculty of \\ Medicine, Ain Shams University, Abbasia square, Cairo, Egypt. \\ ${ }^{5}$ Department of Chest Medicine, Faculty of Medicine, Ain Shams University, Abbasia \\ square, Cairo, Egypt. \\ ${ }^{6}$ Department of Internal Medicine, Faculty of Medicine, Ain Shams University, Abbasia \\ square, Cairo, Egypt. \\ ${ }^{7}$ Department of Geriatric Medicine and Gerontology, Faculty of Medicine, Ain Shams \\ University, Abbasia square, Cairo, Egypt.
}

Corresponding Author Amira M. AlBalakosy Mostafa A.A. Shamkh

\section{Mobile:}

01221977455

01022723991

\section{E mail:}

drbalakosy@gmail.co $m$;

masrawy_ainshams@y ahoo.com

Key words:

SARS-CoV-2; COVID19 pandemic; Measles $\operatorname{Ig} G$
Background and study aim: Epidemiological data reported lower death rates of COVID-19 cases in countries with higher \& recent coverage by measles containing vaccines. In this study we aim to identify measles IgG titer in COVID-19 patients \& correlate it with disease severity.

Patients and Method: This is a Crosssectional study where 78 patients admitted to Ain Shams University Quarantine hospitals with positive PCR for SARS-CoV-2 were enrolled. All patients underwent quantification of serum measles IgG titer. Then classified according to the COVID-19 severity into mild, moderate and severe.

Results: Measles IgG was positive in 53 patients (68\%) with median of 1600 (IQR 1000-or3100), borderline in 18 patients (23\%) with median 250 (IQR 200-250)

\section{INTRODUCTION}

Coronavirus disease 2019 (COVID19) that has caused a dramatic effect on the world's health and economic state, is caused by the novel emergent Severe Acute Respiratory Syndrome Coronavirus 2 (SARS-CoV-2), a $\beta$ coronavirus, which is one type of the coronaviruses family [1]. It is an and negative in seven patients (9\%) with median 100 (IQR 80-120). Patients with positive measles $\mathrm{IgG}$ were significantly older (56 \pm 16 years) than those with negative measles $\operatorname{IgG}$ ( $48 \pm 15$ years) $(\mathrm{P}=0.03)$.No significant difference was found in measles $\operatorname{IgG}$ titer between mild , moderate and severe COVID19 cases. Intensity of pulmonary involvement by CT chest was not correlated with measles IgG titer. The median of measles IgG titer of the ICU admitted patients and those who were not, was 1150 (IQR=600$3500)$ and 1050 (IQR=200-1800) respectively $(\mathrm{p}=0.46)$. No difference in measles IgG titer between patients who recovered or died.

Conclusion: Severity of COVID-19 disease and its outcome seem to be unaffected by measles IgG titer.

enveloped positive-stranded RNA virus [2] whose genes encode four proteins the spike $(\mathrm{S})$, membrane $(\mathrm{M})$, nucleocapsid protein (N), and envelope (E) proteins [3].

The spike protein is a glycoprotein that gives the virus its characteristic crown shape and is used by the virus for binding \& fusion with the host cell 
membrane [4]. In addition, the spike protein carries the major antigenic determinants responsible for production of neutralizing antibodies [5]. SARS-CoV-2 spike glycoproteins share structural similarities with measles virus fusion proteins with $20 \%$ sequence homology confirmed by molecular modeling [6].

Severity of COVID-19 disease ranges from mild to moderate, severe \& critical [7]. During the COVID-19 pandemic, children usually develop mild symptoms compared to adults. An explanation for why children are protected from COVID-19 complications in spite of the fact that they are more susceptible to infections is the comprehensive vaccination programs that are globally implemented [8]. Vaccinations reinforce innate immunity through the production of interferons \& natural killer cells (NK). IFN have potent antiviral action, while NK limit disease severity by targeting infected cells [8]. In addition a specific protection could be provided by some vaccines like measles vaccine due to the structural similarity between SARS-CoV-2 and measles virus, antibody mediated cross protection could be produced. Measles vaccine is a live attenuated vaccine that is safe and highly effective as it induces life-long immunity after one or two injections, WHO recommends that all children should receive measles vaccine either alone or in combination as the standard for all national immunization programs [9].

On the other hand, older age is associated with increased disease severity and mortality where the risk of death among individuals 80 years and older was 20-fold that among individuals 50 to 59 years old [10], lack of coverage with MMR has been postulated to be a reason for the more severe form of COVID-19 in elderly as the vaccine was first introduced in 1971 [11].

In this study we aim to identify measles IgG titer in COVID-19 patients \& correlate it with disease severity.

\section{PATIENTS AND METHODS}

Study design: This is a cross-sectional study.

Study settings: This is a single center study done at Ain Shams Quarantine Hospitals.

Study patients: Patients with confirmed diagnosis of COVID-19.

\section{End points:}

The primary end-point of the study is either recovery or death of the patients.

\section{Sample size}

All patients with PCR proven COVID-19 infection at Ain Shams Quarantine Hospitals.

\section{Inclusion Criteria:}

SARS-CoV-2 infected patients confirmed by positive PCR of throat swabs.

Age $>18$ years.

\section{Exclusion criteria:}

The only exclusion criterion was refusal to participate in the study.

Patient assessment: All patients were subjected to

- History taking.

- Demographic data (age-gender).

- Existence of co-morbidity (diabetes mellitus, hypertension, chronic kidney disease, cardiovascular diseases, chronic lung diseases, chronic liver disease, cancer or immunosuppression).

- Presenting symptoms (Fever, cough, sputum production, dyspnea, rhinorrhea, nasal congestion, sore throat, fatigue, headache, loss of smell or taste, diarrhea $\&$ nausea).

- Clinical evaluation including vital data \& Oxygen saturation by pulse oximeter.

- Laboratory investigations were done for all participants including complete blood picture with differential (CBC), C-reactive protein (CRP), d-dimer, ferritin, AST, ALT, and creatinine.

- Nasal and oropharyngeal swab for detection of SARS-CoV-2 virus: nasal and oropharyngeal swabs were done using dacron swabs with plastic shafts (Sigma virocult (medical wire, UK). The 2 swabs were put in same viral transport media (VTM) after breaking their shafts. Swabs in VTM were transferred immediately to the lab in ice box, if delay happens samples were put in the fridge in 2-8 $\mathrm{C}^{\circ}$ as advised by Center for Diseases Control (CDC) [12]. Real time PCR for detection of SARS-CoV-2 was done through extraction of RNA from swabs in VTM by automatic extractor QIAcube connect (QIAGEN, Germany) using viasure RNA-DNA extraction kit (CerTest BIOTEC, Spain) then amplified using RT-PCR and 
detected using fluorescent reporter dye probes specific for SARS-CoV-2 by thermal cycler CFX96TM IVD Real-Time PCR Detection System (BIO-RAD, USA) using manufacturer instructions in 120 minutes [13].

- Chest imaging was done according to Ain Shams hospital consensus protocol for management of COVID19, all included patients did high-resolution CT chest on presentation for detection of ground glass appearance and/or consolidation. The COVID-19 Reporting and Data System (CORADS) was used to categorize pulmonary involvement [14].

- Included patients were classified according to disease severity [7] into 3 groups:

- Patients with mild disease: Symptomatic patients without radiological evidence of viral pneumonia or hypoxia.

- Patients with moderate disease: patients with clinical signs of pneumonia (fever, cough, dyspnea, fast breathing) but not severe pneumonia, $\mathrm{SpO}_{2} \geq 93 \%$ on room air.

- Patients with severe disease: patients with clinical signs of pneumonia (e.g. fever, cough, dyspnea, fast breathing) and $\mathrm{SpO} 2<93 \%$ on room air.

- Quantitative evaluation of Measles IgG: Serum was collected from samples then was put in aliquots and put in $-20 \mathrm{C}^{0}$ for 2 weeks. The measles virus $\operatorname{IgG}$ titer was determined quantitatively by ELISA kit (IBL, GERMANY) in patients' serum on STAT PHAX 2001 ELISA reader. The obtained optical density (OD) of the standards (y-axis, linear) was plotted against its concentration (x-axis, logarithmic) on semi-logarithmic graph paper. For the calculation of the standard curve, each signal of the standards was applied. The concentration of the samples was read from the standard curve [15].

\section{Interpretation of results:}

\begin{tabular}{|c|c|c|}
\hline Method & Range & Interpretation \\
\hline $\begin{array}{l}\text { Quantitative } \\
\text { (Standard curve) }\end{array}$ & $\begin{array}{l}>300 \\
\mathrm{mIU} / \mathrm{mL}\end{array}$ & Positive \\
\hline & $\begin{array}{l}200-300 \\
\mathrm{mIU} / \mathrm{mL}\end{array}$ & Borderline \\
\hline & $\begin{array}{l}<200 \\
\mathrm{mIU} / \mathrm{mL}\end{array}$ & Negative \\
\hline
\end{tabular}

\section{Statistical Methods:}

Analysis of data was done using SPSS program version 23. To describe the studied patients, quantitative data were presented as mean and standard deviation (median and IQR for nonparametric data). Qualitative data were presented as count and percentage. One-way ANOVA test was used to compare quantitative data between different groups then Post Hoc test was used to detect the difference between individual groups. Kruskal Wallis test was used for non-parametric data. Mann Whitney U test was used to compare non-parametric quantitative data between two independent groups. Chi-Square and Fisher exact tests were used to compare qualitative data between different groups. Spearman's correlation test was used to compare correlation between continuous variables. $\mathrm{P}$ value $\leq 0.05$ was considered statistically significant.

\section{RESULTS}

\section{Study participants:}

This is a Cross-sectional study done at Ain Shams University Quarantine hospitals, which included 78 COVID-19 patients, 41 females (53\%) and 37 males (47\%). Main presenting symptoms at admission were fever and dyspnea in 38 patients (49\%), followed by dyspnea only in 21 patients $(27 \%)$ and diarrhea with or without fever in 10 patients $(12.6 \%)$.

All included patients had positive PCR for SARS-CoV-2, done by nasal and oropharyngeal swabs at presentation to our hospital.

According to our hospital consensus protocol CT chest was done to the majority (71) of the included patients, which revealed ground glass appearance in 55 patients $(77.6 \%)$. Treatment was given according to the national protocol standard care as hydroxychloroquine based therapy.

\section{Patients according to severity of COVID 19 infection}

Included patients were stratified according to COVID-19 disease severity into 3 groups, mild (13 patients), moderate (30 patients) and severe (35 patients), main characteristics and laboratory investigations of the 3 groups are illustrated in tables (1) and (2). Significant differences between the 3 groups existed in age, associated co-morbidity, serum ferritin level and oxygen saturation at room air. 


\section{Measles IgG titer}

Measles IgG was positive in 53 patients $(68 \%)$ with median 1600 (IQR 1000-3100), borderline in 18 patients $(23 \%)$ with median 250 (IQR 200$250)$ and negative in 7 patients $(9 \%)$ with median 100 (IQR 80-120). The age of patients with positive measles $\operatorname{IgG}$ (titer>300) was $56 \pm 16$ while the age of patients with negative or borderline measles IgG (titer <300) was $48 \pm 15$, with statistically significant difference $(\mathrm{P}=0.03)$.

No significant difference was found in measles IgG titer between mild, moderate and severe cases table (3).

There is a significant correlation between measles IgG titer and lymphocytic count, ALT and total bilirubin. High measles $\operatorname{IgG}$ titer is associated with lower lymphocytic count and low ALT but with increased total bilirubin table (4).

Intensity of pulmonary involvement by CT chest was not related to measles IgG titer table (5).

During hospitalization, 12 out of the 78 patients included $(15 \%)$ were admitted to the intensive care unit, the median of measles IgG titer in the ICU admitted patients was 1150 (IQR $=600$ 3500), while it was 1050 (IQR=200-1800) in patients who were not admitted to ICU, with no significant difference $(\mathrm{P}=0.46)$.

Three of the included patients died who were all severe COVID-19 cases, no significant difference in measles $\operatorname{IgG}$ titer between those who recovered or died, figure (1).

Table (1): Patient characteristics of the 3 studied groups.

\begin{tabular}{|c|c|c|c|c|c|c|c|c|c|}
\hline & & \multicolumn{2}{|c|}{$\begin{array}{c}\text { Mild } \\
(\mathrm{N}=13)\end{array}$} & \multicolumn{2}{|c|}{$\begin{array}{c}\text { Moderate } \\
(\mathrm{N}=\mathbf{3 0})\end{array}$} & \multicolumn{2}{|c|}{$\begin{array}{l}\text { Severe } \\
(\mathrm{N}=35)\end{array}$} & \multirow[t]{2}{*}{$\mathbf{F}$} & \multirow[t]{2}{*}{$P$ value } \\
\hline & & Mean & SD & Mean & SD & Mean & SD & & \\
\hline \multirow{2}{*}{\multicolumn{2}{|c|}{ Age }} & 41.00 & 14.13 & 54.97 & 18.05 & 56.60 & 12.60 & 7.80 & $0.01 \mathrm{HS}$ \\
\hline & & $\mathbf{N}$ & $\%$ & $\mathbf{N}$ & $\%$ & $\mathbf{N}$ & $\%$ & $\mathbf{X}^{2}$ & P value \\
\hline \multirow{2}{*}{ Gender } & Female & 5 & $38.5 \%$ & 20 & $66.7 \%$ & 16 & $45.7 \%$ & \multirow{2}{*}{4.09} & \multirow{2}{*}{$0.86 \mathrm{NS}$} \\
\hline & Male & 8 & $61.5 \%$ & 10 & $33.3 \%$ & 19 & $54.3 \%$ & & \\
\hline \multirow{2}{*}{ DM } & Yes & 0 & $0.0 \%$ & 7 & $23.3 \%$ & 15 & $42.9 \%$ & \multirow{2}{*}{9.17} & \multirow{2}{*}{$0.003 \mathrm{HS}$} \\
\hline & No & 13 & $100 \%$ & 23 & $76.7 \%$ & 20 & $57.1 \%$ & & \\
\hline \multirow{2}{*}{ HTN } & Yes & 0 & $0.0 \%$ & 8 & $26.7 \%$ & 11 & $31.4 \%$ & \multirow{2}{*}{5.22} & \multirow{2}{*}{$0.04 \mathrm{~S}$} \\
\hline & No & 13 & $100 \%$ & 22 & $73.3 \%$ & 24 & $68.6 \%$ & & \\
\hline \multirow{2}{*}{ CKD } & Yes & 0 & $0.0 \%$ & 0 & $0.0 \%$ & 1 & $2.9 \%$ & \multirow[t]{2}{*}{1.50} & \multirow{2}{*}{$0.62 \mathrm{NS}$} \\
\hline & No & 13 & $100 \%$ & 30 & $100 \%$ & 34 & $97.1 \%$ & & \\
\hline \multirow{2}{*}{ IHD } & Yes & 0 & $0.0 \%$ & 2 & $6.7 \%$ & 7 & $20.0 \%$ & \multirow[t]{2}{*}{3.99} & \multirow{2}{*}{$0.05 \mathrm{~S}$} \\
\hline & No & 13 & $100 \%$ & 28 & $93.3 \%$ & 28 & $80.0 \%$ & & \\
\hline \multirow[b]{2}{*}{ CPD } & Yes & 1 & $7.7 \%$ & 2 & $6.9 \%$ & 4 & $12.5 \%$ & \multirow[t]{2}{*}{0.64} & \multirow{2}{*}{$0.61 \mathrm{NS}$} \\
\hline & No & 12 & $92.3 \%$ & 27 & $93.1 \%$ & 28 & $87.5 \%$ & & \\
\hline CLD & Yes & 3 & $23.1 \%$ & 0 & $0.0 \%$ & 0 & $0.0 \%$ & 8.92 & $0.004 \mathrm{HS}$ \\
\hline
\end{tabular}


Table (2): Laboratory investigations of the 3 groups.

\begin{tabular}{|l|c|c|c|c|c|c|c|}
\hline \multirow{2}{*}{} & \multicolumn{2}{|c|}{$\begin{array}{c}\text { Mild } \\
\text { (N=13) }\end{array}$} & \multicolumn{2}{c|}{$\begin{array}{c}\text { Moderate } \\
\text { (N=30) }\end{array}$} & \multicolumn{2}{c|}{$\begin{array}{c}\text { Severe } \\
\text { (N=35) }\end{array}$} & \multirow{2}{*}{ P value } \\
\cline { 2 - 8 } & Mean & SD & Mean & SD & Mean & SD & \\
\hline Hb (gm/dl) & 12.58 & 2.93 & 10.83 & 2.09 & 12.38 & 1.90 & 0.47 \\
\hline TLC (/uL) & 8.78 & 3.55 & 7.54 & 3.16 & 7.78 & 3.37 & 0.49 \\
\hline Lymphocytes (/uL) & 1.82 & 0.59 & 1.37 & 0.6 & 1.45 & 0.78 & 0.23 \\
\hline PLT (/uL) & 218 & 74.59 & 253.15 & 103.01 & 251.74 & 104.08 & 0.44 \\
\hline ASST $^{\#}(\mathbf{U} / \mathbf{L})$ & 26.5 & $21.50-35.00$ & 27.50 & $21.00-39.00$ & 27.00 & $23.00-40.00$ & 0.94 \\
\hline $\mathbf{A L T}^{\#}$ (U/L) & 22 & $17.00-32.00$ & 27.50 & $20.00-77.00$ & 27.00 & $19.00-45.50$ & 0.67 \\
\hline Total Bil $(\mathbf{m g} / \mathbf{d l})$ & 0.65 & 0.1 & 0.61 & 0.36 & 0.68 & 0.24 & 0.78 \\
\hline Direct Bil (mg/dl) & 0.15 & 0.07 & 0.23 & 0.14 & 0.16 & 0.09 & 0.79 \\
\hline Albumin $(\mathbf{g m} / \mathbf{d l})$ & 3.4 & 0.59 & 3.57 & 0.46 & 3.37 & 0.68 & 0.7 \\
\hline
\end{tabular}

Table (3): Relation between COVID 19 severity and Measles IgG titre:

\begin{tabular}{|c|c|c|c|c|c|c|c|}
\hline & \multicolumn{2}{|c|}{$\begin{array}{c}\text { Mild } \\
(\mathrm{N}=13)\end{array}$} & \multicolumn{2}{|c|}{$\begin{array}{c}\text { Moderate } \\
(\mathrm{N}=30)\end{array}$} & \multicolumn{2}{|c|}{$\begin{array}{l}\text { Severe } \\
(\mathrm{N}=35)\end{array}$} & \multirow[t]{2}{*}{$P$ value } \\
\hline & Median & IQR & Median & IQR & Median & IQR & \\
\hline $\begin{array}{l}\text { measles IgG titre } \\
(\mathrm{mIU} / \mathrm{ml})\end{array}$ & 1000 & $150-1100$ & 1000 & $230-1600$ & 1300 & $200-3500$ & 0.28 \\
\hline & $\mathbf{N}$ & $\%$ & $\mathbf{N}$ & $\%$ & $\mathbf{N}$ & $\%$ & P value \\
\hline Negative & 4 & $30.8 \%$ & 6 & $20.0 \%$ & 8 & $22.9 \%$ & \multirow{3}{*}{0.47} \\
\hline Borderline & 1 & $7.7 \%$ & 5 & $16.7 \%$ & 1 & $2.9 \%$ & \\
\hline Positive & 8 & $61.5 \%$ & 19 & $63.3 \%$ & 26 & $74.3 \%$ & \\
\hline
\end{tabular}

Table (4): Correlation between measles IgG titre and laboratory investigations.

\begin{tabular}{|c|c|c|}
\hline & & measles IgG titre $(\mathrm{mIU} / \mathrm{ml})$ \\
\hline \multirow{2}{*}{ Hb (gm/dl) } & $\mathbf{r}$ & 0.143 \\
\hline & P value & 0.240 \\
\hline \multirow{2}{*}{ TLC $(/ \mathbf{u L})$} & $\mathbf{r}$ & -0.142 \\
\hline & $P$ value & 0.222 \\
\hline \multirow{2}{*}{ Lymphocytes(/uL) } & $\mathbf{r}$ & -0.252 \\
\hline & $P$ value & 0.028 \\
\hline \multirow{2}{*}{ PLT(/uL) } & $\mathbf{r}$ & -0.014 \\
\hline & P value & 0.907 \\
\hline \multirow{2}{*}{$\operatorname{AST}(\mathbf{U} / \mathbf{L})$} & $\mathbf{r}$ & 0.058 \\
\hline & P value & 0.747 \\
\hline \multirow{2}{*}{$\operatorname{ALT}(\mathbf{U} / \mathbf{L})$} & $\mathbf{r}$ & -0.371 \\
\hline & P value & 0.031 \\
\hline \multirow{2}{*}{ Total Bil(mg/dl) } & $\mathbf{r}$ & 0.532 \\
\hline & $P$ value & 0.034 \\
\hline Direct Bil(mg/dl) & $\mathbf{r}$ & 0.386 \\
\hline
\end{tabular}

Table (5): Relation between CT chest findings and measles IgG titre.

\begin{tabular}{|l|l|c|c|c|c|}
\hline \multicolumn{2}{|c|}{} & \multicolumn{2}{|c|}{$\begin{array}{c}\text { measles virus IgG antibody } \\
\text { titre }(\mathbf{m I U} / \mathbf{m l})\end{array}$} & \multirow{2}{*}{$\mathbf{X}^{\mathbf{2}}$} & \multirow{2}{*}{ P value } \\
\cline { 3 - 4 } \multicolumn{2}{|c|}{} & Median & $\mathbf{I Q R}$ & & \\
\hline \multirow{3}{*}{ CORADS } & CORADS 1 & 1875 & $100-5000$ & & \multirow{3}{*}{0.97} \\
\cline { 2 - 4 } & CORADS 2 & 1000 & $1000-1000$ & \\
\cline { 2 - 4 } & CORADS 3 & 1300 & $200-1900$ & & \\
\cline { 2 - 4 } & CORADS 4 & 1050 & $215-1900$ & & \\
\hline
\end{tabular}




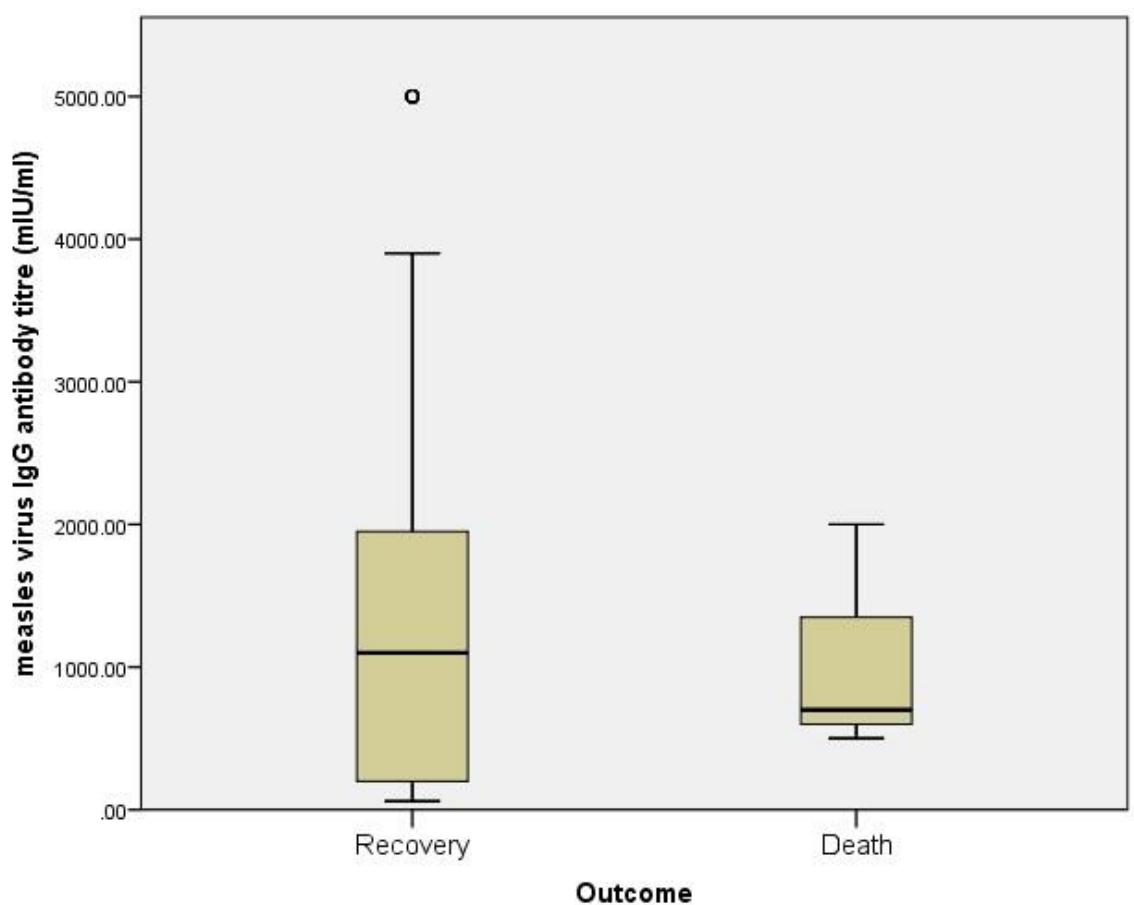

Figure (1):

Legend: Relation between measles IgG titre and COVID-19 disease outcome.

Caption: There was no significant difference regarding measles IgG titer between COVID-19 patients who recovered and those who died.

\section{DISCUSSION}

During the race to find valid vaccine against COVID-19 disease, multiple theories have emerged. Live attenuated vaccines including Mycobacterium bovis (BCG) and Measles Mumps Rubella vaccines (MMR) have been proposed to provide protection against SARSCoV-2 [16].

Additionally, epidemiological data reported lower death rates of COVID-19 cases in countries with higher \& recent coverage with measles containing vaccines [17]. Also live measles vaccine has previously been considered in studies as a base for other coronavirus vaccines including SAR [18].

In this study we measured measles IgG titer in COVID-19 patients in an attempt to discover the impact of immunity against measles on COVID19 disease.

The majority $(68 \%)$ of our patients were positive for measles IgG and were equally distributed among mild, moderate and severe COVID-19 cases. Patients with positive measles IgG were older than those with negative measles IgG, this can be attributed to the fact that monovalent measles vaccine was introduced in Egypt in 1977, and measles vaccination coverage increased from $50 \%$ to $90 \%$ from 1980 to 1999 [19], therefore older population was likely to have acquired wild measles infection in which recovery is associated with sustained levels of neutralizing antibody and life-long protective immunity [20].

Researchers have suggested that MMR vaccine can inhibit or reduce the severe lung inflammation and sepsis associated with COVID-19 through the induction of myeloidderived suppressor cells (MDSCs) [21]. In our study pulmonary involvement by CT chest was not correlated with measles IgG titer, also no significant difference in the level of measles $\operatorname{IgG}$ titer between mild, moderate \& severe COVID19 cases was found.

Increased rubella $\mathrm{IgG}$ titer in SARS-CoV-2 infected patients was correlated with disease burden, the secondary immune response might be responsible for increased antibody production knowing that rubella virus also share antigen homology with SARS-CoV-2 [6]. Whereas our study showed that high measles IgG is associated with lower lymphocytic count. As 
lymphocytopenia has been proven to correlate with COVID19 disease severity and is a prognostic marker for ICU admission [22,23], we may assume that severe COVID-19 might be accompanied with increased production of measles IgG, however it was not clinically evident in our patients where severe cases had measles $\operatorname{IgG}$ titer similar to mild and moderate cases .

Finally, we could not find significant difference in the level of measles IgG titer between patients who recovered and those who died, therefore the current study could not prove the hypothesis of the protective role of measles vaccine.

Limitations of the current study is the small number of included patients especially mild COVID-19 cases because usually mild cases are not hospitalized and receive medical care at home.

In conclusion, although structural similarity between measles virus \& SARS-CoV-2 exists \& researchers have postulated that measles vaccine might be protective against COVID-19, we could not confirm the clinical significance of the immune status against measles in COVID-19 patients.

Conflicts of interests: The authors declare that they have no conflicts of interests.

Funding: This research did not receive any specific grant from funding agencies in the public, commercial, or not-for-profit sectors.

Acknowledgement: Laboratory Staff members at Ain Shams University Hospitals.

\section{Study Highlight:}

- Epidemiological data reported lower death rates of COVID-19 cases in countries with higher \& recent coverage with measles containing vaccines

- The majority of our patients were positive for measles IgG

- In the current study no correlation was found between measles IgG titer and COVID-19 disease severity or outcome.

Ethical Considerations: This study was approved by the ethical committee of faculty of medicine Ain Shams University (15\#6\#2020). Patients were informed that they are included in our study and an informed consent was signed before participation. All procedures were done in accordance with the Code of Ethics of the World Medical Association (Declaration of Helsinki) for experiments in humans, 2013.

\section{REFERENCES}

1. Gorbalenya A., Baker S., Baric R., de Groot R., Drosten C., Gulyaeva A., et al. The species Severe acute respiratory syndrome-related coronavirus: classifying 2019-nCoV and naming it SARS-CoV2. Nat Microbiol 2020; 5: 536-544.

2. Masters P., Perlman S. Coronaviridae: Fields Virology. 6th ed. Lippincott Williams \& Wilkins: Wolters Kluwer; 2013.

3. McIntosh K, Peiris J. Coronaviruses: Clinical Virology. $3^{\text {rd }}$ ed. Washington DC: ASM Press; 2009.

4. Ibrahim I., Abdelmalek D., Elshahat M., Elfiky A. COVID-19 spike-host cell receptor GRP78 binding site prediction. Journal of Infection 2020; 80: 554-562.

5. Petit C., Melancon J., Chouljenko V., Colgrove R., Farzan M., Knipe D., et al. Genetic analysis of the SARS-coronavirus spike glycoprotein functional domains involved in cell-surface expression and cell-to-cell fusion. Virology 2005; 341: $215-230$.

6. Sidiq K., Sabir D., Ali S., Kodzius R. Does early childhood vaccination protect against COVID-19? Front Mol Biosci 2020; 7: 120.

7. World Health Organization. Clinical management of COVID-19. interim guidance. 2020. https://www.who.int/publications/i/item/clinicalmanagement-of-covid-19. Last accessed on $28^{\text {th }}$ of December, 2020.

8. Anbarasu A., Ramaiah S., Livingstone P. Vaccine repurposing approach for preventing COVID 19: can MMR vaccines reduce morbidity and mortality? Hum Vaccin Immunother 2020; 16: 2217-2218.

9. World Health Organization. Measles . In :Vaccine and Disease. Immunization, Vaccines and Biologicals. https://www.who.int/immunization/ diseases/measles/en/. Last accessed on $30^{\text {th }}$ of November, 2020.

10. Williamson E., Walker A., Bhaskaran K., Bacon S., Bates C., Morton C., et al. Factors associated with COVID-19-related death using Open SAFELY. Nature 2020; 584: 430-436.

11. Abbas K., Procter S., van Zandvoort K., Clark A., Funk S., Mengistu T., et al. Routine childhood immunisation during the COVID-19 pandemic in Africa: a benefit-risk analysis of health benefits versus excess risk of SARS-CoV-2 infection. Lancet Glob Health 2020; 8: e1264-e1272. 
12. CDC, 2020: Interim Guidelines for Collecting, Handling, and Testing Clinical Specimens for COVID-19.

https://www.cdc.gov/coronavirus/2019-

ncov/lab/guidelines-clinical-specimens.html. Last accessed on $10^{\text {th }}$ of January, 2021.

13. Tan W., Zhao X., Ma X., Wang W., Niu P., Xu W., et al.. A novel coronavirus genome identified in a cluster of pneumonia cases - Wuhan, China 2019- 2020. China CDC Weekly 2020; 2 :61-62.

14. Prokop M., van Everdingen W., van Rees Vellinga T., Quarles van Ufford J., Stöger L., Beenen L., et al. CO-RADS-A categorical CT assessment scheme for patients with suspected COVID-19: definition and evaluation. Radiology 2020; $296: 97-104$.

15. Tischer A., Andrews N., Kafatos G., Nardone A., Berbers G., Davidkin I., et al. Standardization of measles, mumps and rubella assays to enable comparisons of seroprevalence data across 21 European countries and Australia. Epidemiol Infect 2007; 135 :787-798.

16. Aaby P., Benn C. Developing the concept of beneficial non-specific effect of live vaccines with epidemiological studies. Clin Microbiol Infect $2019 ; 25: 1459-1467$.

17. World Health Organization. Global and regional immunization profile. 2020 https://www.who.int/immunization/monitoring_su rveillance/data. Last accessed on $30^{\text {th }}$ of November, 2020.

18. Escriou N., Callendret B., Lorin V., Combredet C., Marianneau P., Février M. et al. Protection from SARS coronavirus conferred by live measles vaccine expressing the spike glycoprotein. Virology 2014; 452 :32-41.

19. El Sayed N., Kandeel N., Barakat I., Moussa I., Alexander J., Naouri B. et al. Progress toward measles and rubella elimination in Egypt. $J$ Infect Dis 2011; 204 :S318-S324.

20. Griffin D. The immune response in measles: virus control, clearance and protective immunity. Viruses 2016; 8 :282.

21. Fidel P., Noverr M. Could an unrelated live attenuated vaccine serve as a preventive measure to dampen septic inflammation associated with COVID-19 infection? MBio 2020; 11 :e0090700920 .

22. Wark P., Lau R., Norat T., Kampman E. Magnesium intake and colorectal tumor risk: a case-control study and meta-analysis. Am J Clin Nutr 2012; 96 :622-631.

23. Wagner J., DuPont A., Larson S., Cash B., Farooq A. Absolute lymphocyte count is a prognostic marker in Covid-19: A retrospective cohort review. Int J Lab Hematol 2020; 42 :761-765. 